\title{
Positive and Negative Experiences, E-safety and Sharing with Others: Surfing the Internet and Social Networks and the Correlations Between Experiences, Self-image and Computer Skills Among Children and Adolescents
}

\author{
Gila Cohen Zilka ${ }^{1}$ \\ ${ }^{1}$ Achva Academic College, Bar-Ilan University, Israel \\ Correspondence: Gila Cohen Zilka. E-mail: gila.zilka@gmail.com
}

Received: July 2, $2021 \quad$ Accepted: August 20, $2021 \quad$ Online Published: August 30, 2021

doi:10.5539/ass.v17n9p1 URL: https://doi.org/10.5539/ass.v17n9p1

\begin{abstract}
In light of the many major changes in the lives of children and adolescents due to digital developments, this study sought to examine positive and negative experiences, e-safety and sharing with others while surfing the internet and especially social networks from the point of view of children and adolescents. The study also examined the correlation between these experiences, self-image and computer skills. Participating in this mixed-method study were 373 children and teenagers, who were divided into three age groups. The findings showed a positive correlation between self-image, the level of computer skills and the degree of internet use. The measure of self-esteem was found to correlate positively with the parameters of social networks surfing except for the parameter of negative experiences. Social networks and internet use among 16-18-year-olds was found to be higher than among younger children, with a rise in the number of teenagers' negative experiences that corresponded to the rise in use. The adolescents also mentioned they had been exposed to violent content at a higher rate than the younger groups.
\end{abstract}

Keywords: e-safety, computer skills, social networks, children, adolescents, internet, safety

\section{Introduction}

In light of the many major changes in the lives of children and adolescents due to digital developments, this study sought to examine positive and negative experiences, e-safety and sharing with others while surfing the internet and especially social networks from the point of view of children and adolescents. We also wished to learn about the correlation between these experiences, self-image and computer skills.

\subsection{Digital Environment}

Different age groups are affected by changing factors that shape members of that age group such as the life environment, technological developments, shared experiences and topics, significant local and global events, and so forth. Children and youth were born into the digital era, the era of smartphones, Facebook, etc. They are called 'digital natives' because they were born after the broad assimilation of digital technologies. They were born into an environment with extensive daily use of the smartphone, the internet and technology in general (Carter, 2018; Chicioreanu \& Amza, 2018; McCrindle, 2009). Scholars (Carter, 2018; Chicioreanu \& Amza, 2018; McCrindle, 2009; Zilka, 2018a, 2018b, 2018d, 2019b, 2020b) write that this generation, makes extensive use of technology in all areas of life. The scholars note that one of the characteristics of this generation is 'globalization', starting from the consumption of music, fashion, food, entertainment, culture, and global connections, etc. However, they experience greater uncertainty and obscurity than earlier generations. Scholars (Carter, 2018; Turner, 2015) highlight the great use they make of mobile digital technologies such as smartphones or tablets rather than desktop computers. Their phones are their main source of online information. While the previous generation used the phone mainly for communication, this generation also uses many apps and non-verbal symbols such as emojis. This generation's skills in digital communication are much faster than the previous generation, likewise the scope of their social presence and the nature of their digital interactions. One of the main characteristics of this generation, is the extent of the use and exposure to a more diverse range of activities, such as watching video clips, playing games, searching for information. They consume media on a 
daily basis in order to create and maintain social ties, but also to make videos, edit pictures and music, multimedia presentations and content. They write more than any other generation; they are interested in the writing process and in the final product (Rosen, 2010). They have more social contacts than did previous generations, including ones that cross geographical and cultural borders. Activity on social media constitutes an important part of their lives. It offers opportunities to create social ties, keep updated, share information, and have fun with other people. They use media to openly express their autonomy (Asterhan \& Bouton, 2018; Bauerlein, 2008; Carter, 2018; Chicioreanu \& Amza, 2018; Rosenberg \& Asterhan, 2018; Shatto \& Erwin, 2016; Turner, 2015; Zilka, 2016, 2019b, 2020a, 2020b, 2020c).

\subsection{E-safety and Online Bullying}

One of the most worrisome issues is that of e-safety, in other words, online bullying, violation of the right to privacy, exposure to inappropriate or violent content, or content that incites hatred and exclusion, use of obscenities, making contact with strangers, etc. (Zilka, 2017a, 2018b, 2019a). Scholars (Livingstone \& Görzig, 2014; Livingstone \& Smith, 2014; Zilka, 2017a, 2018a, 2018b) define online bullying as harmful activity designed to hurt another person or other communities via textual, auditory and visual messages using a variety of digital tools. The most common forms of this are harassment, hurtful messages, slander, curses, insults, threats, in order to damage the victim's social connections, etc.; identity theft and impersonation, use of the victim's personal details such as username and password in order to carry out actions in the victim's name, spread the victim's personal content or use the victim's name to spread false content, etc.; revealing private and intimate details about another person, thereby violating their right to privacy; digital tracing and gathering of data about the victim and publishing the information gathered in order to harm or threaten the victim, etc.; exclusion and boycotting of the victim or of a community, etc. Most of the victims of sexual abuse online are aged 13-17 and the attackers seek to seduce adolescents who publish personal information online in order to uncover information about their sexuality (Wolak et al., 2008).

This study sought to examine positive and negative experiences, e-safety and sharing with others, surfing the internet and social networks in particular from the perspective of children and adolescents, and to learn about the correlations between self-image and computer skills.

Research variables:

Social networks - positive experiences

Social networks - negative experiences

Social networks - e-safety

Social networks - sharing with others

Self-image

Level of computer skills

Degree of computer and internet use

Research questions:

What are the characteristics of the positive and negative experiences of surfing the internet and social networks in particular from the perspective of the children and adolescents?

What are the characteristics of e-safety and sharing with others when surfing the internet and social networks in particular from the perspective of the children and adolescents?

Are there correlations between positive experiences / negative experiences and self-image, computer skills, and what are the correlations between positive experiences / negative experiences and self-image, and computer skills.

\section{Method}

This is a mixed-method study with particular emphasis on quantitative research, using data gathered in 2017-2018. Quantitative analysis was used in this study, as was ontological methodology for the qualitative analysis.

For the quantitative analysis, tests and correlations were performed on the constructed variables, and on these and the age of the respondents, as well as a comparison with demographic variables. A preliminary test of correlations among all the constructed variables, correlations between these and the age of the respondents and a comparison between boys and girls were performed. An ANOVA was performed to compare age groups. Means 
and distributions of the background variables and computer use variables were also performed.

Ontological qualitative analysis was used to interpret the reality from the perspective of the children and youth. Discourse analysis was conducted on the findings obtained on the basis of the approaches of Adler and Adler (2008), Atkinson and Delamont (2006), and Hammersley (2008). Distinct elements were identified and themes were formulated. The process was iterative and continuous, and eventually led to unified themes sensitive to the context and the place of constructing reality: emphasis was placed on understanding and on the complexity of the positive and negative experiences, e-safety and sharing with others, surfing the internet and social networks in particular, and the connection between self-image and computer skills. Opposing, complementary and explanatory themes were worded according to the approach of

Baskarada (2014) Braun and Clarke (2006) Pope and Mays (2009), and Spencer et al.(2003).

Questionnaires were given to participants after they, their parents, and the school administration agreed that their children could participate in the study and consented to do so.

The study received approval from the institutional review board (IRB) of the Academic College.

\subsection{Sample}

Participants in the study were 373 children and adolescents, who were divided into three age groups: 123 young children aged 7 - 12; 118 children aged 13-15; 115 adolescents aged 16-18. There were 156 boys and 212 girls. The sample covered various socio-demographic regions across Israel.

The children and adolescents expressed their willingness to take part in the study of their own free will. The children's parents were approached and were asked to give their consent to filling out the form. After the parents signed, the questionnaires were distributed, and each participant received an explanation of the questionnaire and how to fill it out.

\subsection{Research Tools}

1. Demographic details such as: age, gender, country of birth, social-ethnic sector (e.g. Jewish Arab; secular/religious).

2. Rogers' self-image questionnaire (1967). The questionnaire consists of ten statements where each subject chooses the answer that suits him/her best on a scale from 1 to 4 : completely disagree - fully agree. Sample statements: Overall I am satisfied with myself; Sometimes I think I am no good at all; I feel I have some good qualities; I would like to have more self-respect; I take a positive attitude towards myself. The reliability of the ten items was tested after inversion and was found to be good (Cronbach's $\alpha=0.77$ ). One score was created the average of the ten items, so that a higher score signified a better self-image.

3. Use of computer and internet. The questionnaires were based on those of Ofcom - Office of Communications (2010), Livingstone et al. (2012), Livingstone and Bober, (2005), and Livingstone (2013). The questionnaire contained 13 questions on a scale with 5 options: I use the internet to: surf the web; search for general information, use databases; for study purposes; Downloading music/films/games; shopping; leisure activities; participating in social networks (WhatsApp, Facebook / Forums / Communities / Discussion groups); visual communication via webcam; phone calls. Since the respondents were asked about the degree of use the internet for various purposes, it is important to mention that it is the sum of all the uses. A higher score indicates more use of the internet in general, in addition to the score for each separate use.

4. Computer skills: The questionnaires were based on those of Ofcom - Office of Communications (2010), Livingstone et al. (2012), Livingstone and Bober, (2005), and Livingstone (2013) "How do you rate your mastery of ... The questionnaire contained 12 questions on a scale of five options from no mastery to very high mastery. The skills: basic computer use (e.g. operating a computer, using a printer, etc.); surfing the net; downloading pictures, films and music from the net; using a search engine; use of computer video games; use of social networks and instant messaging software (e.g., Facebook, WhatsApp, chat, messenger and Skype). The reliability was high: Cronbach's $\alpha=0.90$. The reliability of all the questions examining the level of computer use for various applications and software programs (how do you estimate your mastery of ...) was found to be very high between items $(0.90)$, hence a variable was created that was an average of all the items. A higher score indicates greater mastery of computer skills.

5. Social networks (e.g. Facebook, WhatsApp, chat, messenger and Skype). The questionnaire contained 13 questions on a scale of five options: from 'not at all' to 'a very great extent'. The questions were divided into four parameters: positive experiences, negative experiences, e-safety and sharing with others. Each of the dimensions was constructed as an average of the items affiliated with it. 
The positive experiences questions were: Does participating in social networks help you solve problems in daily life, enable you to express yourself, keep updated on your friends' activities and share the information you want to share conveniently? To what extent does participating in social networks make your daily routine easier? Cronbach's $\alpha=0.82$.

The negative experiences questions were: Do social networks create problems in your daily life? To what extent have you been exposed to violent content on social networks? Cronbach's $\alpha=0.65$.

The questions on the experience of e-safety were: To what extent are you aware of your level of privacy on social networks? To what extent do you define yourself as a 'smart user' of social networks? To what extent are you aware of the risks of surfing the internet in general and of social networks in particular? To what extent do you feel you need tools to cope with problems on social networks? Cronbach's $\alpha=0.76$.

The questions about sharing with others were: To what extent do you consult others about coping with problems on social networks - with parents, siblings, friends? Cronbach's $\alpha=0.74$.

Personal interviews: A total of 90 children and adolescents out of those who completed the questionnaires were interviewed. Interviewees were asked questions to clarify the findings in order to help us understand the reasons behind them.

\section{Findings}

In this section the quantitative findings will be presented by age group and research variables. Following that will be a qualitative analysis of the negative experiences mentioned by the participants.

\subsection{Comparison Between Age Groups According to the Research Variables}

Tables 1 and 2 present the research variables divided into three age groups: 7-12, 13-15 and 16-18. The research variables are: self-image; level of computer skills; degree of computer use and degree of internet use; social networks - positive experience; social networks - negative experience; social networks - e-safety; social networks - sharing with others.

Table 1. Research variables divided by age group on a scale of 0 to 4 .

\begin{tabular}{ccccccc}
\hline & \multicolumn{5}{c}{ Age group } \\
\cline { 2 - 7 } & \multicolumn{2}{c}{$18-16$} & \multicolumn{3}{c}{$15-13$} & \multicolumn{1}{c}{$12-7$} \\
\cline { 2 - 7 } & Average & SD & Average & SD & Average & SD \\
\hline Self-image & 3 & 0.46 & 2.92 & 0.43 & 3.18 & 0.4 \\
Level of computer skills & 3.74 & 0.86 & 3.74 & 0.89 & 3.62 & 0.84 \\
Degree of computer and internet use & 3.78 & 0.95 & 3.58 & 0.85 & 3.56 & 0.96 \\
Social networks - positive experience & 3.19 & 1.05 & 3.25 & 0.95 & 3.24 & 1.14 \\
Social networks - negative experience & 2.68 & 1.04 & 2.35 & 0.8 & 2.27 & 1.1 \\
Social networks - e-safety & 3.56 & 1.05 & 3.67 & 0.92 & 3.58 & 0.95 \\
Social networks - sharing with others & 2.41 & 0.99 & 2.27 & 0.95 & 2.67 & 0.96 \\
\hline
\end{tabular}

Table 2. ANOVA test comparing between the age groups

\begin{tabular}{|c|c|c|c|c|c|}
\hline & \multicolumn{3}{|c|}{ ANOVA } & \multirow[b]{2}{*}{$\mathrm{F}$} & \multirow[b]{2}{*}{ Sig } \\
\hline & Sum of Squares & df & Mean Square & & \\
\hline \multicolumn{6}{|l|}{ Self-image } \\
\hline Between Groups & 4.052 & 2 & 2.026 & 11.038 & 0.000 \\
\hline Within Groups & 64.058 & 349 & 0.184 & & \\
\hline Total & 68.11 & 351 & & & \\
\hline \multicolumn{6}{|c|}{ Level of computer skills } \\
\hline Between Groups & 1.019 & 2 & 0.509 & 0.684 & 0.506 \\
\hline Within Groups & 263.123 & 353 & 0.745 & & \\
\hline Total & 264.142 & 355 & & & \\
\hline \multicolumn{6}{|c|}{ Degree of computer and internet use } \\
\hline Between Groups & 691.264 & 2 & 345.632 & 7.861 & 0.000 \\
\hline Within Groups & 15520.49 & 353 & 43.967 & & \\
\hline Total & 16211.75 & 355 & & & \\
\hline
\end{tabular}




\begin{tabular}{|c|c|c|c|c|c|}
\hline Social networks - positive experience & & & & & \\
\hline Between Groups & 0.303 & 2 & 0.152 & 0.137 & 0.872 \\
\hline Within Groups & 390.489 & 353 & 1.106 & & \\
\hline Total & 390.423 & 355 & & & \\
\hline \multicolumn{6}{|l|}{ Social networks - negative experience } \\
\hline Between Groups & 11.027 & 2 & 5.513 & 5.635 & 0.004 \\
\hline Within Groups & 345.397 & 353 & 0.978 & & \\
\hline Total & 356.423 & 355 & & & \\
\hline \multicolumn{6}{|l|}{ Social networks - e-safety } \\
\hline Between Groups & 0.866 & 2 & 0.433 & 0.458 & 0.633 \\
\hline Within Groups & 333.789 & 353 & 0.946 & & \\
\hline Total & 334.654 & 355 & & & \\
\hline \multicolumn{6}{|l|}{ Social networks - sharing with others } \\
\hline Between Groups & 9.768 & 2 & 4.884 & 5.242 & 0.006 \\
\hline Within Groups & 328.895 & 353 & 0.932 & & \\
\hline Total & 338.662 & 355 & & & \\
\hline
\end{tabular}

Tables 1 and 2 show there were significant differences between the age groups for self-image $(f(2,349)=11.038$, $\mathrm{P}<0.1)$. A post-hoc Scheffe test revealed that the self-image of the young children aged 7-12 $(S D=.40, M E=3.18)$ was higher than for the other two age groups. Significant differences between the age groups were also found for the degree of internet use $(\mathrm{f}(2,353)=7.861, \mathrm{P}<0.1)$. A post-hoc Scheffe test revealed that the highest degree of internet use was found among the group of 16-18 year-old adolescents $(S D=7.73, M E=3.78)$. Significant differences between the age groups were also found for the use of social networks - negative experience $(\mathrm{f}(2,353)=5.635, \mathrm{P}<0.4)$. A post-hoc Scheffe test revealed that the group of 16-18 year-old adolescents reported the highest level of negative experience on social networks $(S D=1.04, M E=2.68)$. Furthermore, significant differences between the age groups were also found for social networks - sharing with others $(f(2,353)=5.242$, $\mathrm{P}<0.6)$. A post-hoc Scheffe test revealed that the young children $(S D=0.96, M E=2.67)$ tended to share their experiences on social networks the most while the group of 13-15 year-olds ( $S D=0.95, M E=2.27$ ) reported on the lowest level of sharing, leaving the group of 16-18 year-olds in the middle.

\subsection{Correlations Between the Research Variables}

The analysis indicates a positive correlation between self-image and level of skills $(\mathrm{r}(363)=.267, \mathrm{P}<0.1)$ and a positive correlation between the degree of internet use $(\mathrm{r}(363)=.165, \mathrm{P}<0.1)$. Additionally, correlations were tested among the four sub-variables of social networks: a positive correlation $(\mathrm{r}(363)=.155, \mathrm{P}<0.3)$ was found between self-image and positive experience, between self-image and e-safety $(\mathrm{r}(364)=.271, \mathrm{P}<0.1)$, and between self-image and sharing with others $(\mathrm{r}(364)=.255, \mathrm{P}<0.1)$. There was also a positive correlation between the level of computer skills with a positive surfing experience $(\mathrm{r}(368)=.360, \mathrm{P}<0.1)$, a negative surfing experience $(\mathrm{r}(368)=.260, \mathrm{P}<0.1)$, surfing e-safety $(\mathrm{r}(368)=.440, \mathrm{P}<0.1)$, and with sharing with others $(\mathrm{r}(368)=.268, \mathrm{P}<0.1)$. A further positive correlation was found between the degree of internet use and social networks - positive experience $(\mathrm{r}(368)=.361, \mathrm{P}<0.1)$, negative experience $(\mathrm{r}(368)=.317, \mathrm{P}<0.1)$, and sharing with others $(\mathrm{r}(368)=.328$, $\mathrm{P}<0.1)$. One can see that the measure of self-image correlates positively with all social network parameters except for negative experience, where there is no significant correlation, and that the level of skill correlates positively with all social network parameters. Moreover, one can see that the degree of internet use correlates positively with all social network parameters except e-safety.

An analysis conducted to examine the correlations between the four social network skills revealed a positive correlation between positive and negative experiences and e-safety on social networks $(\mathrm{r}(368)=.371, \mathrm{P}<0.1)$. No correlation was found between negative experience and e-safety. The level of sharing on social networks correlated positively with the other three parameters of positive experience $(\mathrm{r}(368)=.352, \mathrm{P}<0.1)$, negative experience $(\mathrm{r}(368)=.350, \mathrm{P}<0.1)$, and e-safety $(\mathrm{r}(368)=.247, \mathrm{P}<0.1)$.

\section{Predictive models}

In Step 1 the variables inserted were age, level of computer skills, level of internet use, and self-image. In Step 2 the remaining variables were inserted: e-safety, positive and negative experiences on the internet. The model was found to explain $27.5 \%$ of the variance and all steps were significant. In Step 3, the variables of self-image, level of computer and internet use, negative experiences on social networks and e-safety were found to predict the 
degree of sharing.

\subsection{Qualitative Analysis of the Negative Experiences Mentioned by the Research Subjects}

Four main themes emerged from the qualitative analysis.

The line between sharing with others and "tattling". This difficulty was mentioned by $74 \%$ of the participants, at a high level among 13-15-year-olds (84\%), more than among the other groups. The participants shared different events that occurred, during which they felt a need to tell someone what was happening, but were afraid that doing so would be interpreted as tattling. For example, a 14-year-old boy wrote that someone had posted horrible things about a girl in his class on their class group. The girl didn't respond to what was written about her, but he could see that she had opened the messages and read them. He noticed that after the cruel words had been shared, she stopped coming to school. He really wanted to tell his parents or a teacher at school about what had happened on the social network, but he was very afraid that this would be interpreted as tattling. He contacted the girl who was attacked and asked her if she had told anyone what had happened. The girl refused to tell anyone about what they had written about her on the social network.

The line between private or intimate and public. This difficulty was mentioned by $72 \%$ of the participants, at a higher rate among 16-18 year-olds (80\%). For example, a 16 year-old girl mentioned in the interview that she had accompanied her mother to a gynecologist. Someone saw her and posted a picture of her near the clinic on the social networks and other teenagers started posting guesses about the meaning of her visit to the gynecologist along with cynical and humiliating comments and so forth. The girl said that she didn't respond to the others' messages, but she read them over and over again. She felt very hurt. She refused to go to school for a few days following the incident.

A 16-year-old girl said that she didn't go to school and when her friend asked her why, she said she had an outbreak of pimples on her face. Her friend told her it didn't sound so bad, so she sent her friend a selfie picture of her face, which she felt made her look odd. Her friend posted it to the class group and asked the members of the group what they thought of it. Is that so bad? Then a whole jeering conversation started in the group. The girl felt betrayed, humiliated and angry. During a conversation she had with her friend, her friend didn't understand why she was angry and said she didn't feel she had violated the girl's privacy.

The line between the need to express an opinion and verbal violence, intimidation, ostracism, spreading rumors, posting hurtful content, etc. This difficulty was mentioned by $87 \%$ of the participants. We found that the line between freedom of speech and hurting other isn't clear. For example, a 12 year-old boy said that a classmate of his posted a short and embarrassing film in which another classmate was an unwilling star. The boy said he felt angry and so he wrote in the comments section that he thought the film was a horrible thing to do and should deleted from the group. To his surprise, he was attacked by the other group members and afterwards he was removed from the class group.

The line between humor, slander, and spreading rumors, pictures and videos. This difficulty was mentioned by $89 \%$ of the participants. It appears that what one person interprets as humor, another interprets as humiliation. The boundaries between humor, slander and humiliation are not clear. For example, a 15-year-old boy said that he came back from gym class, slipped and fell in the school hallway and his pants fell down a bit. He said that some friends who were near him helped him get up. After a while he found out that another boy had filmed the whole thing and mainly emphasized the area of his pants and posted the short and embarrassing film to the class group. He was hurt when he saw the film and when he read the comments posted by other members of the group. He posted a comment to the group about it being an unfriendly thing to do. Then the members of the group wrote in response that it was "all in fun," a joke, and that he shouldn't act like a baby, that it was high time he understood what humor was, that humor is good for one's health, etc.

\section{Discussion}

In this study we examine the positive and negative experiences as well as e-safety while surfing the internet and social networks in particular, from the point of view of children and adolescents, and to learn about the relationship between these experiences, self-image and computer skills.

The findings show a positive correlation between self-image, the level of computer skills and the measure of internet usage. In other words, the higher the level of self-image, the higher the level of computer skills and internet use. Correlations of the four sub-variables of social networks were also tested. A positive correlation was found between self-image and positive experience, a positive correlation between self-image and e-safety and between self-image and sharing with others. The measure of self-esteem correlated positively with all social network parameters except that of negative experiences, where there was no clear correlation. 
The amount of Internet usage generally and social network use in particular among 16-18 year-olds was found to be higher than among groups of younger children so that the higher the usage of social networks and the Internet in general, the more negative experiences there are; more so than among younger children. The older adolescents mentioned they had been exposed to violent content to a greater extent than did the younger groups. They also mentioned that social networks in particular caused problems in their daily lives, to a greater extent than did the younger groups. Similarly, they mentioned having a variety of social problems on social networks, shaming, the exclusion of other teenagers from the various groups and the activities that are planned on social networks and mentioned negative experiences at a higher rate than positive ones. The fear of shaming alongside wanting to get the latest updates on everything that's going on creates a psychologically stressful situation for them and they feel the need to check their phones constantly. Similar findings about the complexity adolescents experience in digital environments in general and on social networks in particular have appeared in other studies (Lim, 2016; Livingstone et al., 2014; Zilka, 2018a, 2018b, 2018c). The findings of this and earlier studies (Livingstone, 2014; Zilka, 2018a, 2018b, 2018c) show that negative experiences derive mainly from communication among group or classmates and not from communication with strangers. Children and adolescents usually protect themselves from outsiders (who are not members of their group), and their negative experiences are the result of communicating with friends and acquaintances. Hence, one must emphasize the importance of treating people with dignity and respecting their privacy.

Researchers (Birch \& Ladd, 1997, 1998; Zilka, 2014, 2015, 2017a, 2017b, 2017c, 2020a, 2020c) say that adolescence is a time characterized by having to cope with many physical, emotional, psychological and social changes taking place. That is why it is important that teenagers have an environment that allows them to feel belonging, protectedness, growth, interest, efficacy, challenge, success and feedback, an environment that can enable meaningful interactions, positive experiences and success. They need to create a feeling of self-worth as a result of experiences that give them a feeling of being needed, a feeling of being able to make a meaningful contribution to their surroundings and have a chance to express their skills and to receive feedback that they are appreciated by the people around them; to enable feeling socially connected as a result of experiences that give them a feeling of belonging and close and supportive friendships and being socially popular, offering them meaningful interactions that lead to involvement and performing important tasks at home, in school and in the community. The findings of this study show that social networks in particular and the internet in general offer adolescents a sense of belonging, growth, interest, efficacy, challenge, success and meaningful interactions. But at the same time, social networks in particular and the Internet in general also set teenagers up to have negative experiences and a sense of being unprotected.

The findings further show that young children (aged 7-12) tend to tell others about their experiences on social networks in particular and the Internet in general, whereas among older children (aged 13-15) the level of sharing goes down, but among adolescents (aged 16-18) the level of experience-sharing goes up again. However, they do not share with those older than themselves, but rather with their peers and friends. This finding is especially important in light of the other findings that associate abundant surfing with negative experiences and an exposure to violent content among adolescents. Sharing with others can help them cope with negative experiences, avoid the dangers that await them while surfing the net. That being said, sharing, especially with friends, sometimes causes intimate content to become public and thus brings about shaming and a violation of the child's privacy. Many participants mentioned that they shared something intimate with friends and those friends spread that information on the internet, thus causing them to feel upset and angry and alienated towards the members of the groups where the content was posted. Therefore, children should be taught how to tell the difference between sharing something with their parents or other meaningful adults, and sharing something with their friend and peers. Furthermore, they should be taught the difference between public content and maintaining their own privacy and that of their friends.

This difficulty was fond among $72 \%$ of the subjects, with a high level among 16-18-year-olds (80\%). Other difficulties that emerged were the blurring of boundaries between sharing with others and "snitching". The subjects mentioned various events in which they felt a need to share but were afraid that doing slo would be interpreted as snitching. This difficulty appeared among $74 \%$ of the subjects with a high level among 13-15 year olds (84\%), more than in the other groups. It appears that there is a blurring of boundaries between freedom of expression - the desire to express an opinion - and verbal violence, scare tactics, boycotting, spreading rumors, uploading hurtful content and so forth. This difficulty appeared among $87 \%$ of the subjects. Apparently the boundary between freedom of expression and hurting others is unclear. It seems hard to distinguish between humor and slander, spreading rumors photos and videos. This difficulty appeared among $89 \%$ of the subjects. It also seems that what one person considers humor, another will see as humiliation. Thus the boundary between 
humor and slander and humiliation is not clear. The findings of this study reinforce those of earlier studies (Zilka, 2018a, 2018b, 2018c).

From the predictive models executed in this study, it emerges that self-image, the level of computer and internet use, negative experiences on social networks and e-safety were found to predict the degree of sharing. Hence, we can conclude that cultivating among children and adolescents a sense of belonging, acceptance, attentiveness and assistance might lead to more sharing.

In summation, children and teenagers should be encouraged to tell meaningful adults about what is happening on social networks and to help them know the difference between sharing and "tattling." Telling an adult can help them cope with negative content and experiences that harm their mental well-being. They should also be taught the difference between telling an adult and telling a peer or friend. Furthermore, they should be taught the difference between sharing public content and maintaining their own privacy and that of their friends. These messages should be taught in an organized and structured manner by parents, teachers and other meaningful adults in the children's lives. On the internet in general and on social networks in particular there may be situations when the boundaries between what is private and what is public, between intimacy and sharing; between adapting to an environment and its norms and making autonomous choices become blurred. Balanced incorrectly, adapting can turn into doing what everyone else does and autonomy can become avoidance and even alienation. There are also fine lines between humor, slander and spreading rumors; between the need to express an opinion and verbal violence such as intimidation, ostracism, spreading rumors, posting hurtful content.

\section{References}

Adler, P. A., \& Adler, P. (2008). Of Rhetoric and Representation: The Four Faces of Ethnography. The Quarterly Sociological, 49(1), 1-30. https://doi.org/10.1111/j.1533-8525.2007.00104.X

Asterhan, C. S., \& Bouton, E. (2018). Teenage peer-to-peer knowledge sharing through social network sites in secondary schools. Computers \& Education, 110, 16-34. https://doi.org/10.1016/j.compedu.2017.03.007

Atkinson, E., \& Delamont, S. (2006). In the roiling smoke: Qualitative inquiry and contested fields. I. J. of Qualitative Studies in Education, 19(6), 747-755. https://doi.org/10.1080/09518390600975974

Baskarada, S. (2014). Qualitative case study guidelines. The Qualitative Report, 19, 1e18. Retrieved from https://ssrn.com/abstract=2559424

Bauerlein, M. (2008). The Dumbest Generation: How the Digital Age Stupefies Young Americans and Jeopardizes Our Future (Or, Don 't Trust Anyone Under 30). New York: Penguin Tarcher. Retrieved from https://ascelibrary.org/doi/full/10.1061/(ASCE)1532-6748(2009)9:2(100)

Birch, S. H., \& Ladd, G. W. (1997). The teacher-child relationship and children's early school adjustment. Journal of School Psychology, 35(1), 61-79. https://doi.org/10.1016/S0022-4405(96)00029-5

Birch, S. H., \& Ladd, G. W. (1998). Children's interpersonal behaviors and teacher-child relationships. Developmental Psychology, 34(5), 934-946. Retrieved from https://psycnet.apa.org/buy/1998-10846-011

Braun, V., \& Clarke, V. (2006). Using thematic analysis in psychology. Qualitative Research in Psychology, 3(2), 77e101. https://doi.org/10.1191/ 1478088706qp063oa

Buhrmester, D. (1990). Intimacy of friendship, interpersonal competence, and adjustment during preadolescence and adolescence. Child Development, 61(4), 1101-1111. https://doi.org/10.2307/1130878

Carter, T. (2018). Preparing generation Z for the teaching profession. Srate Journal, 27(1), 1-8. Retrieved from https://eric.ed.gov/?id=EJ1166694

Chicioreanu, T. D., \& Amza, C. G. (2018). Adapting your teaching to accommodate the Net Generation /Z-Generation of learners. The 14th International Scientific Conference eLearning and Software for Education, Bucharest, April 19-20. Retrieved from https:/web.a.ebscohost.com/abstract?direct=true\&pro file $=$ ehost $\&$ scope $=$ site $\&$ authtype $=$ crawler $\&$ jrnl $=2066026 X \& A N=129483722 \& \mathrm{~h}=\mathrm{hvzhtg} \% 2 \mathrm{fq} 7 \mathrm{Y} 10 \mathrm{IEokbzj}$ IMWisX4o6A60wtQSy72tpa7grrlB5uHAVUajA6nndU96u39OBI86LbNErhK2m\%2bipHxg\%3d\%3d\&crl= c\&resultNs=AdminWebAuth\&resultLocal=ErrCrlNotAuth\&crlhashurl=login. aspx $\% 3 \mathrm{fdirect} \% 3 \mathrm{dtrue} \% 26 \mathrm{pr}$ ofile\%3dehost\%26scope \%3dsite\%26authtype\%3dcrawler\%26jrnl\%3d2066026X\%26AN\%3d129483722

Hammersley, M. (2008). Questioning Qualitative Research: Critical Essays. London, UK: Sage.

Lim. S. S. (2016). Through the tablet glass: Transcendent parenting in an era of mobile media and cloud computing. Journal of Children and Media, 10(1), 21-29. https://doi.org/10.1080/17482798.2015.1121896

Livingstone, S. (2013). Online risk, harm and vulnerability: Reflections on the evidence base for child internet 
safety policy. ZER: Journal of Communication Studies, 18(35), 13-28. http://eprints.lse.ac.uk/62278/

Livingstone, S., \& Bober, M. (2005). UK children go online: Final report of key project findings. London: London School of Economics and Political Science. Retrieved from http://eprints.lse.ac.uk/399/

Livingstone, S., \& Görzig, A. (2014). When adolescents receive sexual messages on the Internet: Explaining expe-riences of risk and harm. Computers in Human Behavior, 33, 8-15. https://doi.org/10.1016/j.chb.2013.12.021

Livingstone, S., \& Smith, P. (2014). Annual research review: Children and young people in the digital age: The nature and prevalence of risks, harmful effects, and risk and protective factors, for mobile and Internet usage. Journal of Child Psychology and Psychiatry: Annual Research Review 2014. Online first. https://doi.org/10.1111/jcpp.12197

McCrindle, M. (2009). Beyond Z: meet generation alpha. The ABC of XYZ: Understanding the global generations. Bella Vista, AU: McCrindle Research. Retrieved from https://www.researchgate.net/ publication/328347222_The_ABC_of_XYZ_Understanding_the_Global_Generations

Ofcom - Office of Communications. (2010). UK adults' media literacy report. Retrieved from http://stakeholders.ofcom.org.uk/binaries/research/media-literacy/adults-media-literacy.pdf

Ofcom - Office of Communications. (2016). Children and parents: Media use and attitudes report. Retrieved from https://www.ofcom.org.uk/research-and-data/media-literacy-research/children/children-parents-nov16

Pope, C., \& Mays, N. (2009). Critical reflections on the rise of qualitative research. BMJ, 339, b3425. https://doi.org/10.1136/bmj.b3425

Rogers, C. R. (1967). On Becoming a Person: A Therapist's View of Psychotherapy. London: Constable.

Rosen, L. (2010). Understanding the iGeneration - before the next mini-generation arrives. NiemanReport. Retrieved from https://niemanreports.org/articles/understanding-the-igeneration-before-the-next-minigeneration-arrives/

Rosenberg, H., \& Asterhan, C. S. (2018). “WhatsApp, teacher?"-student perspectives on teacher-student WhatsApp interactions in secondary schools. Journal of Information Technology Education: Research, 17, 205-226. https://doi.org/10.28945/4081

Shatto, B., \& Erwin, K. (2016). Moving on from millennials: Preparing for generation z. The Journal of Continuing in Nursing, 47(6), 253-254. https://doi.org/10.3928/00220124-20160518-05

Spencer, L., Ritchie, J., Lewis, J., \& Dillon, L. (2003). Quality in qualitative evaluation: A framework for assessing research evidence. London: The Cabinet Office.

Turner, A. (2015). Generation Z: Technology and social interest. The Journal of Individual Psychology, 71(2), 103-113. https://doi.org/10.1353/jip.2015.0021

Wolak, J., Finkelhor, D., Mitchell, K., \& Ybarra, M. (2008). Online "Predators" and their Victims: Myths, Realities and Implications for Prevention and Treatment. American Psychologist, 63(2), 111-128. https://doi.org/10.1037/2152-0828.1.S.13

Zilka, C. G. (2014). Empowering Educators \& Mentors in the Social Media Age - The Three Element Way. Butan-Galim. (Hebrew) Tel Aviv: Bitan-Galim.

Zilka, C. G. (2015). Social competence of children at risk: Similarities and differences among the various assessors. In E. Grupper, \& S. Romi, S. (Eds.), Children and adolescents at risk in Israel. Vol 2. The voice of young people and issues faced by child and youth care workers (pp. 113-185). Tel Aviv: MOFET (Hebrew).

Zilka, C. G. (2016). Do online friendships contribute to the social development of children and teenagers? The bright side of the picture. Journal of Humanities and Social Science, 6(8), 102-112.

Zilka, C. G. (2017a). Awareness of eSafety and potential online dangers amongst children and teenagers. Journal of Information Technology Education: Research, 16, 319-338. Retrieved from https://www.informingscience.org/Publications/3864

Zilka, C. G. (2017b). Awareness of ICT capabilities, digital literacy, and use of reflective processes in children who received their first home computer. Journal of Technology Enhanced Learning, 9(1), 80-98. Retrieved from http://www.inderscience.com/info/ingeneral/forthcoming.php?jcode=ijtel

Zilka, C. G. (2017c). The Elements Way: Empowering parents, educators, and mentors in the age of new media. 
Issues in Informing Science and Information Technology, 14, 101-119. https://doi.org/10.28945/3702

Zilka, C. G. (2018a). Always with them: Smartphone use by children, adolescents, and young adults characteristics, habits of use, sharing, and satisfaction of needs. Universal Access in the Information Society (UAIS). https://doi.org/10.1007/s10209-018-0635-3

Zilka, C. G. (2018b). eSafety and sharing habits with family and friends among children and youths. Child and Adolescent Social Work Journal. https://doi.org/10.1007/s10560-018-0573-1

Zilka, C. G. (2018c). E-safety in the use of social networking apps by children, adolescents, and young adults. Interdisciplinary journal of e-Skills and lifelong Learning, 14, 177-190. https://doi.org/10.28945/4136

Zilka, C. G. (2018d). Medium preferences of children and adolescents for content distributed by the media. Interchange (INCH), 49(4), 457-476. https://doi.org/10.1007/s10780-018-9337-2

Zilka, C. G. (2019a). The digital divide: Implications for children and adolescents' eSafety. International Journal of Technology Enhanced Learning, 11(1), 20-35. https://doi.org/10.1504/IJTEL.2019.096736

Zilka, C. G. (2019b). The use of mobile technologies by immigrant adolescents in coping with the new language and with their formal studies. In A. Forkosh-Baruch, \& H. Meishar-Tal (Eds.), Mobile technologies in educational organizations (pp. 192-210). IGI Global, USA.

Zilka, C. G. (2020a). Feelings of belonging or alienation and social emotional perceptions of immigrant youths in the digital age, in comparison with native-born youths. Education and Information Technologies. (Q1) https://doi.org/10.1007/s10639-020-10333-x

Zilka, C. G. (2020b). Teenagers connected to digital environments - what happens when they get to school? Commonalities, similarities and differences from their perspective. Education and Information Technologies, 25, 1743-1758. https://doi.org/10.1007/s10639-019-10052-y

Zilka, C. G. (2020c). Use of social networking applications (SNAs) by immigrant children, adolescents, and young adults. International Journal of Mobile Communication, 18(3), 257-272. https://doi.org/10.1504/IJMC.2020.10017997

\section{Copyrights}

Copyright for this article is retained by the author(s), with first publication rights granted to the journal.

This is an open-access article distributed under the terms and conditions of the Creative Commons Attribution license (http://creativecommons.org/licenses/by/4.0/). 